\title{
Is there a Role for Cash Transfers in Climate Change Adaptation?
}

\author{
Rachel Godfrey Wood
}

\begin{abstract}
This article assesses the potential of cash transfer programmes to contribute to adaptation goals in developing countries. It argues that cash transfers are likely to contribute to adaptive capacity by (1) meeting basic needs; (2) helping the poor respond to climate-related shocks; (3) helping vulnerable households to manage risk and consider investment innovations that increase their adaptive capacity; (4) transferring money for investment in long-term adaptive capacity development; and (5) facilitating mobility and livelihood transitions. While the article acknowledges that cash transfers cannot address all areas of adaptation, these transfers may be a prerequisite for further adaptation to be equitable and effective. When compared with other adaptation options, cash transfers fare well as they are supported by a substantial evidence base, do not require much climate-related information, have a demonstrated potential for scaling up and are likely to gain local acceptance.
\end{abstract}

\section{Introduction}

To date, the climate change adaptation field has developed largely without interacting with the parallel field of social protection, even though existing social policies and interventions may have the potential to contribute to adaptation goals in the most vulnerable countries. Bringing these two fields together has been identified as a key development challenge (Shepherd 2008). This article refers specifically to one type of social protection intervention: cash transfers, which have been shown to have broadly positive impacts on livelihoods in developing countries over the past 15 years (Hanlon et al. 2010).

Until now, the link between cash transfers and adaptation goals has been made only superficially. While it has been suggested that cash transfers could have a role (Heltberg et al. 2008), the ways in which they could contribute to adaptation goals have not been systematically researched. Given that the climate change adaptation field is in its infancy, there is an urgent need to develop evidence-based analyses of policies that can contribute to adaptation goals.

This article posits that cash transfers contribute significantly to adaptation goals, mainly by protecting and increasing adaptive capacity. While cash transfers alone could not resolve all challenges of adaptation, they may contribute to many indirectly, while also increasing the possibility that other policies have a greater chance of achieving positive impacts. Therefore, there is a strong case for cash transfers to be considered a key part of the toolkit of policies to address adaptation needs in developing countries.

\section{Cash transfers}

Cash transfer programmes vary in scale, objectives and implementation. Most are directed to particular groups of the population deemed to need them most, such as poor mothers, the elderly and the disabled.

In the last decade, cash transfers have reached unprecedented levels of popularity in many developing countries. Well-known schemes such as Oportunidades (Mexico), Bolsa Familia (Brazil) and the State Old Age Grant (South Africa) have been maintained and scaled up, with advocates arguing that they contribute to a number of goals. These include positive effects on nutrition, the ability of the poor to manage risk, and multiplier effects in the local economy (see Hanlon et al. 2010 for a summary of these).

It is important to emphasise, however, that there are still significant unresolved debates about cash transfers (even among proponents), 
particularly in relation to conditionality, and about the effectiveness (cost-benefit) of targeting the poorest.

It must also be emphasised that cash is not the only medium for transferring resources to the poor: food, livestock, or agricultural inputs have all been used, at times successfully. Indeed, there may still be instances when distributing resources in kind may be more effective than using cash. Schemes that guarantee employment may also achieve many of the goals that cash transfers aim to do. Nevertheless, this article focuses on cash transfers because of the attention they have received and the emerging consensus that they are often the most desirable means of distributing resources to the poor.

\section{Cash transfers and adaptation goals}

Adaptation to climate change has been described by the Intergovernmental Panel on Climate Change (IPGC) as:

Adjustments in ecological, social and economic systems in response to actual or expected climatic stimuli and their effects or impacts. It refers to changes in processes, practices, and structures to moderate potential damages or to benefit from opportunities associated with climate change (IPGC 2001: 879).

This description encompasses a broad range of policy interventions, the effectiveness of which can be measured in different ways. In order to make an objective assessment of the contribution of cash transfers to adaptation goals, this article narrows the focus to adaptive capacity, which allows for an approach that addresses multiple causes of vulnerability and the immediate needs faced by resource-poor households. This does not mean that further adaptation policies are not necessary, but that 'adaptive capacity' should be the natural focus for social protection policies.

\subsection{Adaptive capacity}

Brooks and Adger (2005: 168) describe adaptive capacity as 'the ability to design and implement effective adaptation strategies, or to react to evolving hazards and stresses so as to reduce the likelihood of the occurrence and/or the magnitude of harmful outcomes resulting from climate-related hazards'. Therefore, adaptive capacity is a prerequisite to successful adaptation, though it does not guarantee it.
Although there is no general consensus regarding the most important determining factors of adaptive capacity, there is an understanding that many of these factors are generic, such as health, education and income (IPCC 2007), most of which are targeted by existing social protection instruments.

\subsection{How do cash transfers support adaptive capacity?}

Based on the available literature on cash transfers, it seems reasonable to assume that they contribute towards adaptive capacity in a number of ways (as follows). At the same time, it is important to emphasise that adaptive capacity is only one component of the wider field of adaptation.

\section{Meeting existing needs}

At the most basic level, cash transfers help destitute households to meet their basic needs. In particular, the role of cash transfers in bringing about better nutritional outcomes which in turn allow for better long-term educational, health and labour productivity has been largely evidenced (see Hanlon et al. 2010, for a review). Those groups identified as being most vulnerable to climate change suffer frequently from nutritional deficits. Prior to one adaptation project in Kenya, for example, 70 per cent of residents were spending 50-98 per cent of their income on food, and over 54 per cent simply did not have enough to eat (Awuor 2009: 104). Apart from the fact that nutrition is a determining factor of adaptive capacity in itself, nutritional deficits are likely to reduce people's desire to consider longer-term issues. In Bangladesh for example, a project manager noted that 'building communities' knowledge of climate change in order to facilitate and motivate adaptation comes up against the practical problem of engaging communities with issues that may not have immediate relevance to their wellbeing' (Rahman 2009: 53). What this remark suggests is that acute and immediate needs must be addressed comprehensively before any long-term pro-poor adaptation can be effective, or even desirable.

\section{Helping the poor to respond to shocks}

Shocks can increase pressures on livelihoods that are already under strain, and access to income can be vital in these situations. Eriksen et al. (2005) for example, found a strong statistical relationship between the ability of people to draw on extra sources of income (via remittances 
or formal wages) and their resilience to droughts in Kenya and Tanzania. As Adger and Vincent (2005) emphasise, not only are the resources to deal with exposure key indicators of adaptive capacity, distribution of those resources across landscapes and populations is also crucial. Therefore, redistributing these resources (globally or nationally) is likely to be a prerequisite to providing the poor with the means to withstand shocks, and cash transfers represent one mechanism for achieving this.

Much of the negative impact of shocks is indirect, by forcing people into necessary but damaging coping strategies, which reduce their adaptive capacity in the long term. Cash transfers can have strong impacts in reducing the pressure for such strategies. For example, in Malawi, a donor-funded scheme was found to significantly reduce pressure for people to get into debt during the 'hungry season' (Devereux $e t$ al. 2006). Importantly, given that the poor often face threats from a variety of climate and nonclimate-related threats, cash transfers can be used to respond to shocks, regardless of whether they are caused by climate change or not.

There is in fact growing evidence that cash transfers are a cost-effective means of distributing resources to people affected by natural disasters. As well as allowing recipients a degree of flexibility to decide how to use these resources, cash transfers can also stimulate local economies (Harvey 2007). But simply using cash transfers for relief is insufficient. Many of the effects of climate change will not be immediate or dramatic enough to catch the attention of relief agencies. Furthermore, there is increasing evidence that the greatest benefits of cash transfers with regards to nutrition, educational attainment and labour productivity accrue to those who are able to participate for sustained amounts of time (Barrientos and Niño-Zarazúa 2010). In a changing and unpredictable climate, there is a strong case for social policy measures to be made available over an extended timeframe and to be in place before disasters occur.

\section{Helping the poor to manage risk}

Even if the poor are not forced into adopting extreme coping strategies, an increased threat of shocks can force them into coping strategies which are low-risk, yet provide low returns. Difficulty in managing risk has itself been identified as a cause of long-term poverty (Heltberg et al. 2008), and can inhibit the ability of the poor to build up their adaptive capacity over time. Moreover, it also restricts their capacity to innovate in ways that improve their livelihoods and respond to climate change, something identified as a key characteristic of adaptive capacity (ACCRA 2010). Cash transfers can give households the financial space to make those decisions and innovate, rather than being forced into coping strategies by circumstances. Evidence that cash transfers have this effect can be seen by the increased ability and willingness to make productive investments and also to migrate. While the adaptation community is partly addressing the issue of risk management with a focus on insurance schemes, this risks missing the point that a basic lack of cash can prevent the poorest from participating in them (IPCG 2007).

\section{Giving the poor money to invest and increase their asset base}

Not only do cash transfers protect whatever adaptive capacity the poor already have by providing them with resources to withstand shocks, they also have a long-term impact by transferring resources which can be invested productively, allowing for sustained improvements of generic adaptive capacity indicators. Cash transfers have been shown to encourage a diverse array of profitable investments which allow households to increase their asset base, as shown by the $45-50$ per cent increase in agricultural spending among cash transfer recipients in Paraguay (Soares et al. 2008). Such productive investments can and do lead to long-term increases in income above and beyond the effect of just the cash transfer, as was demonstrated in one study in Mexico (Gertler $e t$ al. 2006). There is also evidence from South Africa that cash transfers can lead to higher rates of savings and the opening of bank accounts, which are often prerequisites for sustained livelihood improvement (Neves et al. 2009). Therefore, even although the majority of cash transfers are usually used to meet immediate needs, the net income benefits often go beyond the sum of the transfer itself in the long run (see Hanlon et al. 2010: 69-73, for a review).

The extent of this effect is contingent, of course, on the quantity of the transfer. In programmes where the transfer is very small, the amount used for investment is minimal. But successful 
investment also depends on people's skills and the extent to which local opportunities are available for productive investment. Even so, it seems clear that cash transfers increase livelihood options, and the poor generally take advantage of these options in ways that improve their wellbeing. From an adaptation perspective, this leads to positive outcomes: more options, investment opportunities and incomes are likely to lead to greater adaptive capacity.

\section{Facilitating mobility and livelihood transitions}

Climate change could gradually make livelihoods less viable. One response to this could be temporary or permanent migration. The ability to migrate is not always identified in discussions of adaptive capacity, but there is evidence that it is an important strategy in increasing resilience, accumulating assets and responding to a wide range of climate and non-climate-related transformations. For example, there is increasing evidence that children from migrant households have better nutrition than comparable non-migrant households, and that migration improves families' ability to withstand food price shocks (Zezza et al. 2011). In addition, the remittances these migrants send back can also bolster rural livelihoods (Tacoli 2011).

There is evidence that cash transfers, by reducing the transaction costs of migration, and providing a degree of insurance to both migrants and their dependants, could facilitate such mobility and smooth necessary changes or desired livelihood transitions. Evidence suggests they may have encouraged economic migration in Mexico (Azuara 2009) and South Africa (Ardington et al. 2007). To the author's knowledge, no studies have been done on the impact of cash transfers on mobility in the context of climate-related shocks and stresses, although one study in Colombia suggests that cash transfers can help poor families to leave areas suffering from high levels of political violence (Mesnard 2009). On the other hand, programmes that make transfers conditional on working in rural areas, such as India's Mahatma Gandhi National Rural Employment Guarantee Act (MGNREGA), can restrict mobility, as potential migrants may be afraid of losing social assistance once they move to urban areas (Slater 2011).

The argument here is not that cash transfers should be used with a view to increasing migration, but instead that they can increase the options available to the poor to improve their long-term adaptive capacity and respond to stresses - and migration is one strategy for achieving this.

\section{The limits of cash transfers}

This article has argued that although no comprehensive research has been done so far, there is already emerging evidence that cash transfers can contribute to adaptive capacity. However, these cash transfers do not directly address the non-generic determinants (such as institutions, knowledge, innovation or forwardthinking decision-making) that have been identified as key components of adaptive capacity. Furthermore, adaptive capacity alone does not guarantee effective adaptation.

Indeed, decisions taken by individuals can either increase or reduce vulnerability. It is not uncommon for livelihood strategies adopted by the poor to improve their adaptive capacity in terms of generic indicators such as income and educational opportunities, but at the same time increase their vulnerability in other ways. This may include, for example, building houses in ecologically sensitive areas in order to be close to income-generating opportunities. While cash transfers increase people's resources and options within a particular context, they do not change that context, and effective adaptation will also need to remove the structural constraints to adaptation.

Glearly, cash transfers cannot address all the issues relating to adaptation, and should not be expected to. However, even though cash transfers do not contribute directly to other aspects of adaptation, they certainly do not inhibit them. Financial constraints can be barriers to a variety of adaptation policies or innovations, from relatively small health measures to larger and more expensive innovations like irrigation systems and new crop varieties (IPCC 2007). By offering a degree of capital and livelihood security, cash transfers could increase the likelihood that more 'transformative' changes could occur.

\section{How do cash transfers fit into the adaptation policy toolkit?}

It has been argued in this article that cash transfer schemes need to be seriously considered as policy options worthy of adaptation funding. 
However, given that cash transfers can address some (but by no means all) issues relating to adaptation, and that available funding is often limited, it is crucial to consider how they compare with other adaptation interventions. Cash transfers perform well in three further aspects.

\subsection{An evidence-based policy in the face of uncertainty}

In a field shrouded by uncertainty, cash transfers represent a policy that can be virtually guaranteed to increase the adaptive capacity of people most vulnerable to climate change. Assuming these positive outcomes is perfectly reasonable, based on the substantial literature that already exists. Moreover, contributions to such outcomes are likely to be significant, regardless of climate trends, and thus no extensive knowledge or modelling of future climate-related phenomena is necessary for effective implementation. These relative certainties have to be weighed against other adaptation options which have more uncertain outcomes. Currently, many potential adaptation policies (such as irrigation and dam building) are highly risk-prone, require 'lumpy' investments and are based on incomplete information. Nicol and Kaur (2008) go so far as stating that poorly implemented 'adaptation' policies could even induce negative impacts. Therefore, if the idea is for adaptation finance to be used for policies supported by a strong evidence base, cash transfers should be high on the list.

\subsection{Likelihood of gaining local acceptance}

Because they can be used to address both existing needs and multiple causes of vulnerability, cash transfers stand a high chance of being accepted at the local level. Unlike many approaches to climate change adaptation, they do not require beneficiaries to fundamentally change their outlook, or to de-prioritise existing concerns in favour of more abstract and longterm ones. On the contrary, they bolster existing livelihood strategies and increase the options of the poor to improve their welfare, working on the reasonable assumption that this will contribute positively to adaptive capacity.

With regards to governments, the picture is more mixed. Cash transfers have already achieved wide political acceptance across the political spectrum in Latin America and in some southern African countries. Meanwhile, in other parts of Africa, pilot cash transfer programmes have been implemented, although many of these have not been embraced by their countries' Ministries of Finance and therefore remain heavily donor-reliant (Devereux and White 2010). While there is some official support for cash transfer programmes, as can be seen from the Social Policy Framework agreed on in Namibia in 2008, many governments still see social transfers as unaffordable or encouraging a 'culture of dependency'. Moreover, despite their successes, cash transfers are by no means the 'only game in town' when it comes to social policy, and some governments have opted for schemes that transfer assets such as subsidised agricultural inputs, as well as hybrid schemes.

Much of the reticence with respect to cash transfer programmes in less developed countries is due to real fiscal constraints to scaling them up (McCord 2009). As a result, many programmes are limited to small sub-sections of the poor, which can lead to the exclusion of many people in need. Therefore, while there is clearly a need and, in some cases, a demand for cash transfers, there is also an important role for the international community in helping to meet this demand.

\subsection{Implementation and scalability}

The ease with which cash transfer programmes can be scaled up depends on various factors, not least political will. As with any other policy, cash transfers face challenges of governance, particularly given that most countries in regions with the greatest needs are usually those with low government effectiveness. By comparison, projectbased approaches to adaptation struggle to ensure that those benefits accrue to the wider population. Put simply, if the intention is to increase the adaptive capacity of as many people in a relatively short amount of time, cash transfers could be an extremely efficient way of achieving this.

\section{Conclusion}

It has been argued in this article that cash transfers contribute significantly to adaptive capacity, help the poor respond to multiple causes of vulnerability and can facilitate necessary livelihood improvements and transitions. The fact that many of those people most vulnerable to climate change also have the greatest need for social protection makes cash transfers a clear 'no regrets' use of adaptation finance. 
However, beyond the strong practical case for distributing adaptation finance, there is also an ethical question. Given that adaptation is supposed to benefit the people who have done the least to cause climate change and are most likely to be affected by it, who actually has the right to decide how the money which is supposed to remedy its effects is spent? Allowing the poor to have direct control over at least a portion of adaptation finance could be an attractive option in the context of a field that has already seen the development of approaches that are based heavily on the pre-existing agendas of different non-poor actors. Many government plans for adaptation involve large-scale projects which can in certain cases increase the vulnerability of the poor, while NGOs can have a bias in favour of certain livelihoods or solutions. Distributing adaptation finance directly to the poor would take some of

\section{References}

ACGRA (Africa Climate Change Resilience Alliance) (2010) Consultation Document: The ACCRA Local Adaptive Capacity Framework, http://community.eldis.org/.59d669a7/ACCRA $\% 20$ adaptive $\% 20$ capacity $\% 20$ framework $\% 20$ consultation\%20version\%20Oct\%202010.pdf (accessed June 2011)

Adger, W.N. and Vincent, K. (2005) 'Uncertainty in Adaptive Capacity', Comptes Rendus Geoscience 337: 399-410

Ardington, C.; Case, A. and Hosegood, V. (2007) Labour Supply Responses to Large Social Transfers: Longitudinal Evidence from South Africa, NBER Paper, www.princeton.edu/rpds/papers/pdfs/ Case_Ardington_Hosegood_NBER_w13442_ oct07.pdf (accessed June 2011)

Awuor, C. (African Centre for Technology Studies) (2009) 'Increasing Drought in Arid and Semi-Arid Kenya', in J. Ensor and R. Berger (eds), Understanding Climate Change Adaptation: Lessons from Community-Based Approaches, Rugby: Practical Action Publishing

Azuara, O. (2009) Does Poverty Alleviation Increase Migration? Evidence from Mexico, University of Chicago, http://mpra.ub.uni-muenchen.de/ 17599/1/MPRA_paper_17599.pdf (accessed June 2011)

Barrientos, A. and Niño-Zarazúa, M. (2010) Do Social Transfer Programmes have Long-term Effects on Poverty Reduction?, Manchester: Chronic Poverty Research Centre, www.chronicpoverty.org/ uploads/publication_files/PB\%2020.pdf (accessed June 2011) the subjectivity out of adaptation, and allow those who have to live with the consequences of climate change to have an active role in addressing them.

This may seem counter-intuitive, given that knowledge of climate change is heavily concentrated within scientists and 'expert' circles. However, the knowledge required for adaptation is by no means a monopoly of these actors. Even when those affected by climate change are unaware of it as a global phenomenon, they possess valuable knowledge regarding changing local climate patterns, and the ways these interact with their own livelihoods and aspirations. Much of the adaptation literature already places a strong emphasis on the knowledge and agency of the poor, and cash transfers represent a very concrete way of following through with this.

Brooks, N. and Adger, W.N. (2005) 'Assessing and Enhancing Adaptive Capacity', in K. Chopra, R. Leemans, P. Kumar and H. Simons (eds), Adaptation Policy Frameworks for Climate Change: Developing Strategies, Policies and Measures, Cambridge: Cambridge University Press, www.undp.org/gef/documents/publications/ apf-technical-paper07.pdf (accessed June 2011)

Devereux, S. and White, P. (2010) 'Social Protection in Africa: Evidence, Politics and Rights', Poverty and Public Policy 2.3: 53-77, www.psocommons.org/ppp/vol2/iss3/art5/ (accessed June 2011)

Devereux, S.; Mvula, P. and Solomon, C. (2006) After the FACT: An Evaluation of Concern Worldwide's Food and Cash Transfers Project in Three Districts in Malawi, www.ids.ac.uk/ index.cfm?objectid=4F5B3743-0F89-5F9A23853011F138A7F2 (accessed June 2011)

Eriksen, S.H.; Brown, K. and Kelly, P.M. (2005) 'The Dynamics of Vulnerability: Locating Coping Strategies in Kenya and Tanzania', The Geographical Journal 171.4: 287-305

Gertler, P.; Martinez, S. and Rubio-Codina, M. (2006) Investing Cash Transfers to Raise Long Term Living Standards, Policy Research Working Paper 3994, Washington DC: World Bank, www-wds.worldbank.org/servlet/WDSContent Server/WDSP/IB/2006/08/10/ 000016406 20060810124348/Rendered/PDF/wps3994..pdf (accessed June 2011)

Hanlon, J.; Barrientos, A. and Hulme, D. (2010) Just Give Money to the Poor: The Development 
Revolution from the Global South, Sterling VA: Kumarian Press

Harvey, P. (2007) Cash-based Responses in Emergencies, London: Overseas Development Institute (ODI), www.odi.org.uk/resources/download/ 229.pdf (accessed June 2011)

Heltberg, R.; Jørgensen, S.L. and Siegel, P.B. (2008) Climate Change Challenges for Social Protection in Africa, Washington DC: World Bank, http://iopscience.iop.org/17551315/6/41/412025 (accessed June 2011)

IPCC (Intergovernmental Panel on Climate Change) (2007) (Adger, W.N.; Agrawala, S.; Mirza, M.M.Q.; Conde, C.; O’Brien, K.; Pulhin, J.; Pulwarty, R.; Smit, B. and Takahashi, K.) 'Assessment of Adaptation Practices, Options, Constraints and Capacity', in M.L. Parry, O.F. Canziani, J.P. Palutikof, P.J. van der Linden and C.E. Hanson (eds), Climate Change 2007: Impacts, Adaptation and Vulnerability. Contribution of Working Group II to the Fourth Assessment Report of the

Intergovernmental Panel on Climate Change, Cambridge: Cambridge University Press: 717-43

IPGC (Intergovernmental Panel on Climate Change) (2001) (Smit, B.; Pilifosova, O.; Burton, I.; Challenger, B.; Huq, S.; Klein, R.J.T.; Yohe, G.; Adger, W.N.; Downing, N.; Harvey, I.; Kane, S.; Parry, M.; Skinner, M.; Smith, J. and Wandel, J.), 'Adaptation to Climate Change in the Context of Sustainable Development and Equity', Ch. 18 of the Intergovernmental Panel on Climate Change Third Assessment Report Working Group II, Impacts, Adaptation and Vulnerability, www.grida.no/publications/ other/ipcc_tar/?src=/climate/ipcc_tar/wg2/ index.htm (accessed 8 August 2011)

McCord, A. (2009) 'Cash Transfers and Political Economy in sub-Saharan Africa', ODI Project Briefing, www.odi.org.uk/resources/ download/3509.pdf (accessed June 2011)

Mesnard, A. (2009) Migration, Violence and Welfare Programmes in Rural Colombia, IFS Working
Paper, www.ifs.org.uk/wps/wp0919.pdf (accessed June 2011)

Neves, D.; Samson, M.; van Niekerk, I.; Hlathshwayo, S. and du Toit, A. (2009) The Use and Effectiveness of Social Grants in South Africa, Institute for Poverty, Land and Agrarian Studies (PLAAS) and Economic Policy Research Institute (EPRI), executive summary, www.wahenga.net/node/1868 (accessed June 2011)

Nicol, A. and Kaur, N. (2008) 'Climate Change: Getting Adaptation Right', ODI Opinion, www.odi.org.uk/resources/download/2495.pdf (accessed June 2011)

Rahman, K.M.M. (2009) 'River Erosion and Flooding in Northern Bangladesh', in J. Ensor and R. Berger (eds), Understanding Climate Change Adaptation, Rugby: Practical Action Publishing

Shepherd, A. (2008) Think Piece for EADI/DSA/IDS/ Action Aid High Level Policy Forum on MDGs, www.eadi.org/fileadmin/MDG_2015 Publications/Shepherd_THINKPIECEE.pdf (accessed June 2011)

Slater, R. (2011) 'Cash Transfers, Social Protection and Poverty Reduction', International Journal of Social Welfare 20.3: 250-9

Soares, F.V.; Ribas, R.P. and Hirata, G.I. (2008) Achievements and Shortfalls of Conditional Cash Transfers: Impact Evaluation of Paraguay's Tekoparã Programme, Brasilia, Brazil: International Poverty Centre, http://ideas.repec.org/p/ipc/ pubipc/1020735.html (accessed June 2011)

Tacoli, C. (2011) Not Only Climate Change: Mobility, Vulnerability and Socio-economic Transformations in Environmentally Fragile Areas of Bolivia, Senegal and Tanzania, Human Settlements Working Paper Series, London: International Institute for Environment and Development (IIED), http://pubs.iied.org/10590IIED.html?a =C\%20 Tacoli (accessed June 2011)

Zezza, A.; Carletto, C.; Davies, B. and Winters, P. (2011) 'Assessing the Impact of Migration on Food and Nutrition Security', Food Policy 36.1: $1-6$ 